\title{
THE ETHICS OF JOURNALISM
}

\section{INDIVIDUAL, INSTITUTIONAL AND CULTURAL INFLUENCES}

\section{Edited by WENDY N. WYATT}
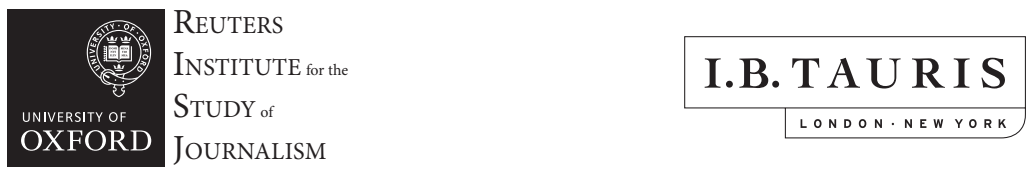

Published by I.B.Tauris \& Co. Ltd in association with

the Reuters Institute for the Study of Journalism, University of Oxford 


\title{
About the Book
}

The landscape in which journalists now work is substantially different to that of the twentieth century. The rise of digital and social media necessitates a new way of considering the ethical questions facing practising journalists. This volume considers the various individual, cultural and institutional influences that have an impact on journalistic ethics today. It also examines the links between ethics and professionalism; the organisational promotion of ethical values; and the tensions between ethics, freedom of information and speech, and the need to disseminate information.

By comparing the theoretical underpinnings of journalistic ethics with a variety of international case studies, this volume provides a comparative global analysis of the ethical challenges faced by the media in the twenty-first century. It will be essential reading for students of journalism and practising journalists.

'This exceptionally well-conceived collection brings together some of the best media ethicists in the field, and succeeds at what few such volumes accomplish: examining journalism ethics in its real-world institutional and sociological context, while exploring and deepening the moral claims that give it stature and nobility as a normative discourse. The result is both sweeping and penetrating, a work of great value to academics and journalists alike.'

Edward Wasserman, Dean, Graduate School of Journalism, University of California, Berkeley

\section{About the Editor}

Wendy N. Wyatt is Associate Professor and Chair of the Department of Communication and Journalism at the University of St. Thomas, Minnesota. Her research interests include media ethics, press criticism and media literacy. She is the author of Critical Conversations: A Theory of Press Criticism, and co-editor (with Kris Bunton) of The Ethics of Reality TV.

\author{
What follows is a short extract from this book. \\ More information can be found at: www.ibtauris.com/reuters
}


The Reuters Institute would like to acknowledge the assistance of Kevin Rafter and Ian Hargreaves as readers on behalf of the Institute.

Published in 2014 by I.B.Tauris \& Co. Ltd

6 Salem Road, London W2 4BU

175 Fifth Avenue, New York NY 10010

www.ibtauris.com

Distributed in the United States and Canada Exclusively by Palgrave Macmillan 175 Fifth Avenue, New York NY 10010

Copyright Editorial Selection and Introduction (c) 2014 Wendy N. Wyatt Copyright Individual Chapters (c) 2014 David S. Allen, Thomas H. Bivins, Elizabeth Blanks Hindman, Jan Lauren Boyles, Tom Clasen, Robert E. Drechsel, Tobias Eberwein, Susanne Fengler, Yael de Haan, Ejvind Hansen, Tony Harcup, Dejan Jontes, Annemarie Landman, Julia Lönnendonker, Carlos Maciá-Barber, Mireya Márquez Ramírez, David Pritchard, Laura Schneider-Mombaur, Karen L. Slattery, Bastiaan Vanacker, Lee Wilkins, Wendy N. Wyatt

The right of Wendy N. Wyatt to be identified as the editor of this work has been asserted by her in accordance with the Copyright, Designs and Patents Act 1988.

All rights reserved. Except for brief quotations in a review, this book, or any part thereof, may not be reproduced, stored in or introduced into a retrieval system, or transmitted, in any form or by any means, electronic, mechanical, photocopying, recording or otherwise, without the prior written permission of the publisher.

ISBN: $9781780766737(\mathrm{HB})$ $9781780766744(\mathrm{~PB})$

A full CIP record for this book is available from the British Library A full CIP record is available from the Library of Congress

Library of Congress Catalog Card Number: available

Typeset in Great Britain by Data Standards Ltd, Frome, Somerset Printed and bound in Great Britain by T.J. International, Padstow, Cornwall 


\section{Contents}

Acknowledgements viii

$\begin{array}{ll}\text { List of Figures } & \text { ix }\end{array}$

List of Contributors $\quad$ x

Introduction $\quad \mathbf{x v}$

Wendy N. Wyatt

1. The Norms that Govern Journalism: An Ecological Approach

David Pritchard

Part I Spheres of Influence: Fostering (or Not) Ethical Journalism

2. The Ethical Newsroom: Where the Individual and the Collective Work Together

Tony Harcup

3. My Newsroom Made Me Do It: The Impact of

Organisational Climate on Ethical Decision-Making

Lee Wilkins

4. Professionalism and Journalism Ethics in

Post-Authoritarian Mexico: Perceptions of News for

Cash, Gifts, and Perks

55

Mireya Márquez Ramírez 
5. Covering the Private Lives of Public Officials: Comparing the United Kingdom, Flanders, and the Netherlands Bastiaan Vanacker

6. Ethics (of Objectivity) and Cultural Authority: Metajournalistic Discourse in a Post-Socialist Context Dejan Jontes

Part II Accountability Mechanisms

7. Journalists, Journalism Ethics, and Media Accountability: A Comparative Survey of 14 European and Arab Countries 85 Susanne Fengler, Tobias Eberwein, Julia Lönnendonker, and Laura Schneider-Mombaur

8. How News Ombudsmen Help Create Ethical and Responsible News Organisations

Carlos Maciá-Barber

9. Do Professionalism and Ethics Reduce or Increase Pressure for Legal Accountability? Robert E. Drechsel

Part III Intersections: Theory and Practice

10. Ethics and Journalistic Standards: An Examination of the Relationship between Journalism Codes of Ethics and Deontological Moral Theory

Karen L. Slattery

11. The Language of Virtue: What Can We Learn from Early Journalism Codes of Ethics?

Thomas H. Bivins

12. The Media and Democracy: Using Democratic Theory in Journalism Ethics

David S. Allen and Elizabeth Blanks Hindman 
Part IV Emerging Issues in a Global, Digital Age

13. Towards Knowledge-Centred Newswork: The Ethics of Newsroom Collaboration in the Digital Era

Yael de Haan, Annemarie Landman, and Jan Lauren Boyles

14. Can the Ethics of the Fourth Estate Persevere in a Global Age?

Ejvind Hansen

15. Ethics in the Age of the Solitary Journalist Wendy N. Wyatt and Tom Clasen

Index 


\section{Acknowledgements}

Thanks, first, to Robert Picard, Director of Research at the Reuters Institute, for asking me to edit this volume. It has been an honour and a pleasure to help bring the work of my colleagues to an audience beyond the scholars and journalists who attended the Oxford conference. Thanks, also, to the faculty in the Department of Communication and Journalism at the University of St Thomas, who were patient with me when I put aside my administrative duties to work on this book. Third, thanks to Tom Clasen, my partner in writing and in life, who is a great supporter and critic (in all the right ways), not to mention a walking dictionary and the best copy editor I know. He has given me incredible help with this project. Finally, on behalf of the book's contributors, thanks to the journalists throughout the world who do ethically admirable work. Good journalism does matter.

Wendy N. Wyatt

January 2014 


\section{Figures}

7.1 Established and innovative media accountability instruments

7.2 Percentage of citizens who consider media outlets to be trustworthy

7.3 Regulation models for the media sector 91

7.4 Countries included in the MediaAcT study 93

7.5 Percentage of respondents who said the media accountability instrument has a 'high' impact or 'very high' impact

7.6 Ratings for company editorial codes 96

$\begin{array}{lll}7.7 & \text { Ratings for press councils }\end{array}$

7.8 Percentage of respondents who reported that the emerging media accountability instrument has a 'high' or 'very high' impact

7.9 Ratings for criticism on social media 100

7.10 Ratings for user comments 101 


\section{Contributors}

David S. Allen is an associate professor in the Department of Journalism, Advertising, and Media Studies at the University of Wisconsin-Milwaukee where he currently serves as chair of the department. He is the author of Democracy, Inc. (2005) and co-editor (with Robert Jensen) of Freeing the First Amendment (1995).

Thomas H. Bivins is the John L. Hulteng Chair in Media Ethics in the School of Journalism and Communication at the University of Oregon where he is the head of the media studies major and graduate certificate programme in communication ethics. He is the author of numerous articles and books on subjects ranging from media ethics to public relations writing.

Elizabeth Blanks Hindman is an associate professor in the Edward R. Murrow College of Communication at Washington State University where she teaches undergraduate and graduate courses in media ethics. She is the author of Rights vs. Responsibilities: The Supreme Court and the Media (1997).

Jan Lauren Boyles is a $\mathrm{PhD}$ fellow and adjunct professor at American University's School of Communication in Washington, DC. In addition to her work as a professional journalist, Boyles has served as a Google Journalism Fellow and as a researcher with the Pew Internet and American Life Project.

Tom Clasen is a writer, editor, and media observer with particular interests in media economics and media literacy. His perceptions of the news industry are influenced by his 35-year career in the business world.

Robert E. Drechsel holds the James E. Burgess Chair in Journalism at the University of Wisconsin-Madison, where he is also an affiliated professor 
of law. His work has focused on the relationship between media law and media ethics, and it has appeared in communication and legal journals. $\mathrm{He}$ holds a $\mathrm{PhD}$ in mass communication from the University of Minnesota.

Tobias Eberwein is a visiting professor of journalism at the Technische Universität Dortmund where he teaches courses in international journalism, online journalism, and media ethics. He acts as scientific officer of the international research project 'Media Accountability and Transparency in Europe' (MediaAcT). His research interests include journalistic quality, media accountability, literary journalism, and comparative journalism research.

Susanne Fengler is a professor of international journalism at the Technische Universität Dortmund and the academic director of the Erich Brost Institute for International Journalism where she coordinates the international research project 'Media Accountability and Transparency in Europe' (MediaAcT). Besides media accountability, her research interests include comparative journalism studies, political journalism, development communication, and economic theory of journalism.

Yael de Haan is a senior researcher at the Utrecht University of Applied Science in the Netherlands. In 2011 she completed her $\mathrm{PhD}$ on media accountability and journalism ethics. In addition to her work as a researcher and senior lecturer at the school of journalism in Utrecht, she is a member of the Dutch press council.

Ejvind Hansen is a research director at the Danish School of Media and Journalism where he focuses on the cultural implications of digital communication. In 2005 he defended his $\mathrm{PhD}$ dissertation, Embedded Critique in a Tensed World, in which he investigates the conditions for critique in the late modern societies. His work is generally situated in the field of critical and post-structuralist theory.

Tony Harcup has worked in mainstream journalism, alternative media, and journalism education. Currently a senior lecturer at the University of Sheffield in the UK, he is the author of The Ethical Journalist (2007), Journalism: Principles and Practice (2009), Newspaper Journalism (2010, with Peter Cole), and Alternative Journalism, Alternative Voices (2013). 
Dejan Jontes is an assistant professor in the Department of Media and Communication Studies, Faculty of Social Sciences, at the University of Ljubljana. His areas of interest include communication theory, media studies, and critical/cultural approaches to popular culture and journalism. His most recent book, published in Slovene, is Journalism as Culture: Myths and Values (2010).

Annemarie Landman is a professional journalist, currently working as a reporter for one of the leading broadcast news organisations in the Netherlands. In addition to her journalism study at the Utrecht University of Applied Science, she passed the master examination (cum laude) in Communication Science at the University of Amsterdam where she researched the influences of the digital era on newsroom collaboration in the Netherlands.

Julia Lönnendonker is a researcher at the Erich Brost Institute for International Journalism. She acts as coordination officer of the international research project 'Media Accountability and Transparency in Europe' (MediaAcT). Her research interests include international and European journalism, foreign correspondence, and European identity studies.

Carlos Maciá-Barber is an associate professor and vice-chair of the Journalism and Media Studies Department at the Carlos III University of Madrid. He is the author of the first doctoral thesis in Spain about news ombudsmen. He is also lead researcher for two journalism ethics projects funded by the Spanish National Research, Development, and Innovation Plan.

Mireya Márquez Ramírez is an assistant professor of journalism studies and media theory at Universidad Iberoamericana, Mexico City. She holds a $\mathrm{PhD}$ in Media and Communications from Goldsmiths, University of London, and an MA in Journalism Studies from Cardiff University, UK. Her research areas include the study of post-authoritarian journalism cultures; reporting practices, news routines, and press history in Mexico; and global media policy in Latin America. She is currently a team member of the Worlds of Journalism Study in Mexico.

David Pritchard is a professor at the University of Wisconsin-Milwaukee. He has been a Fulbright research scholar, a visiting professor at Laval 
University in Canada, and a visiting professor at the French Press Institute in Paris. Before moving into the academic world, Pritchard was a journalist for seven years.

Laura Schneider-Mombaur is a researcher at the Erich Brost Institute for International Journalism. She acts as administrative officer of the international research project 'Media Accountability and Transparency in Europe' (MediaAcT). Her research focuses on accountability, transparency, and self-reflection in journalism, journalism cultures, and comparative journalism research. She also works as a freelance journalist.

Karen L. Slattery chairs the Department of Journalism and Media Studies at Marquette University, Milwaukee, Wisconsin. She received her doctorate from the University of Wisconsin. Her work has appeared in Journalism and Mass Communication Quarterly, Journalism and Communication Monographs, Journal of Mass Media Ethics, and Journal of Broadcasting and Electronic Media.

Bastiaan Vanacker is an associate professor at Loyola University Chicago where he teaches and researches media ethics and law and serves as Director of the Center for Digital Ethics and Policy.

Lee Wilkins, chair of the Department of Communication at Wayne State University, focuses her research on media ethics, media coverage of the environment, and hazards and risks. She is a co-author of one of the country's best-selling college ethics texts, Media Ethics: Issues and Cases, now in its eighth edition with McGraw Hill. Wilkins is the editor of the country's leading academic journal on media ethics, the Journal of Mass Media Ethics.

Wendy N. Wyatt is an associate professor of media ethics and chair of the Department of Communication and Journalism at the University of St. Thomas, Minnesota. Much of her research focuses on issues of media and democracy. She is the author of Critical Conversations: A Theory of Press Criticism (2007) and co-editor (with Kristie Bunton) of The Ethics of Reality TV (2012). She is also book review editor for the Journal of Mass Media Ethics. 


\section{Introduction}

\section{Wendy N. Wyatt}

For anyone interested in making journalism better, it is essential to first sort out what makes journalism the way it is. What are the influences that contribute to journalists' attitudes and actions - to their ethics? Without an understanding of those influences, it is difficult to make recommendations for change meaningful. Through the contributions of nearly two dozen scholars and journalists, this volume aims at building understanding of three primary influences: the individual, the cultural, and the institutional. The book considers not only how the three work independently, but, importantly, how they interact to affect the moral compasses of journalists and the moral standing of the practice as a whole.

Much has been said about individual, institutional, and cultural influences. The autonomous moral agent - the rational individual - forms the basis of Western moral philosophy's three primary traditions: those of the good, the right, and the virtuous. For the Greeks, for Enlightenment thinkers, and for many modern-day ethicists, the focus is on the individual; if we can foster in individuals strong characters or if we can give them the tools to figure out how to do the good or the right thing, we will create moral communities. Therefore, when it comes to theorising about journalism ethics, a focus on individual influences is a solid way forward.

But individuals are not islands, and the extent to which they act independently of other factors can - as we are reminded by ethicists in the feminist and communitarian traditions - be overstated. We are who we are and we act as we do because of others. In other words, we are not as autonomous as we'd like to think we are. Institutional influences, particularly those in the news industry, can be incredibly strong, and robust socialisation can affect even the most independent of journalists. Put simply, an institution can change a person - for better or for worse. 
What's more, an institution can take on an ethical life of its own. Scholars who have written about collective moral agency contend that organisations themselves can be assigned moral personhood. An organisation as a collective (not simply a group of individuals) acts as a moral agent with concomitant rights, duties, and accountabilities.

On top of individual and institutional influences, we add those that derive from culture. Journalists are part and parcel of the culture in which they live and work, and they reflect their own culture's worldview. We readily see this when, for example, we compare journalists from democracies with those from authoritarian states. But differences can be found even among journalists from two like cultures. Journalists in the United Kingdom certainly have ethical compasses that differ from their peers in other democracies. What is justified as ethically acceptable in one place may look quite different in another.

The discipline of journalism ethics developed with a focus on professional ethics - on the values, guiding principles, and codes of the journalism profession. During the last 35 years, questions have revolved around who journalists should be and what those journalists should do, and these questions have almost always considered journalism in a particular situated context. Today, however, foundations are being reimagined: first, by ethicists who contend that we need a global media ethics, which transcends the limitations of place, and, second, by ethicists who advocate for a return to a common morality that focuses on our general moral commitments and our obligations as human beings, rather than our particular role-related responsibilities as journalists. All of this leaves journalism ethics in an interesting theoretical place. What is the proper way - or ways - forward to best understand the influences on journalism ethics? And once that is established, what is the proper way or ways - forward to make normative claims about fostering the most ethically justifiable practice of journalism?

As media ethicists grapple with these questions, they are constantly reminded that the questions are not only abstract and theoretical. Real life intervenes - sometimes with examples of ethically praiseworthy behaviour, the kind that makes us proud to be associated with journalism. We don't focus on those exemplars here (most ethics texts don't) but we can't ignore that journalists and journalism organisations do good work every day. On the other hand, the reason that media ethicists have steady jobs is that the examples we would call ethically praiseworthy are often overshadowed by examples of another kind - behaviour that makes those ethicists and their 
journalist colleagues cringe. What's more, these behaviours are what tend to attract the public's attention. Even if news people and news organisations act daily to serve the public's best interest, that public notices when something goes wrong. It is one of these examples - the phone hacking scandal in the UK and the subsequent Leveson Inquiry into the culture, practice, and ethics of the press - that serves as the origin for this book.

As Lord Justice Leveson, together with his panel of six independent assessors, considered how to best 'guard the guardians', ethicists around the world grappled with what went wrong and how a repeat of history could be prevented. Should the focus be placed on changing the ethical standards of individual journalists? Was this a problem with a single institution, one that tended towards ethical recklessness? Was there something in the culture of UK journalism - one marked by intense competition and more than a little bombast - that led to the scandal? Or, more plausibly, was it some combination of influences? And, of course, what happens next? How can journalism ethicists earn their keep by offering a path forward?

For many, the phone hacking scandal provided yet another concrete example of journalism ethics gone wrong. Interestingly, Lord Leveson noted that the report resulting from his inquiry was the seventh of its kind in fewer than 70 years. The questions it raised were more than interesting academic exercises. Regardless of what transpired during the scandal and what the Leveson Inquiry would later propose, if journalism was to successfully justify itself in the face of harsh and understandable critique, it would need answers or, at the very least, a plan.

So, in September 2012, just as Lord Leveson wrapped up more than a year's worth of evidence collected for his inquiry, a group of nearly 50 scholars and journalists convened at the invitation of the University of Oxford's Reuters Institute for the Study of Journalism to discuss and debate a particularly timely theme: 'Journalism Ethics: Individual, Institutional or Cultural?' When participants met in Oxford with Reuters Director of Research Robert Picard, the tale of the phone hacking scandal - and all of its gruesome details - had unfolded in front of the Leveson Inquiry, but the judgement was still out. Conference participants weren't sure what the end result would be, but we were all interested in exploring what got journalism to that regrettable place and how we could help it make a new turn.

Over the course of two full days at St Anne's College - plus some evening indulgences at the Reuters Institute and at Balliol College - we grappled with issues of where journalists get their ethical compasses, what 
leads to ethically problematic behaviour in newsrooms around the world, and how we might foster more ethically praiseworthy journalism. This volume illustrates just some of the good thinking that went on in Oxford.

The chapters in the book certainly stand on their own; any one could be read in isolation. But there's something to be said about reading the collection as a whole: individual chapters give glimpses; the entire collection gives a more complete story. As you work through, you'll find that journalism ethics is driven by a multitude of complex forces that rank in importance by time, by place, and by other contextual factors. The story, of course, is never a simple one, which, in my mind, is what makes ethics so endlessly intriguing.

\section{Recurring themes}

A number of themes serve as threads that connect the individual chapters and help make sense of the multiple ideas presented:

- Both the descriptive and normative realms matter. Typically, scholarship in journalism ethics falls into two categories: (1) work that describes the ethical landscape and helps make sense of it; (2) work that enters the normative realm by prescribing ethical values, principles, standards, and behaviours. Both approaches are useful; clearly, we must understand before we can recommend. Contributors to this volume help us with both. Some chapters reside in the realm of the descriptive, establishing the landscape of journalism ethics and building the all-important foundations. Others make the move to the normative, offering prescriptions aimed at making journalism better.

- Theory and practice can and should intersect. Moral philosophy serves as the theoretical underpinning of much scholarly work in journalism ethics. Unless that theory can connect to practice, however, the work is merely an academic exercise. Several chapters in the book address how theory can - and, normatively speaking, should - inform practice and how practice can and should exemplify theory. In addition, the volume stretches beyond moral theory and considers the contributions that other kinds of theory - democratic, legal, organisational - can make to the practice of ethical journalism.

- The global, digital age affects journalism ethics. Perhaps the top item on the agenda of media ethicists today is the nature of the global, 
digital age; a sophisticated discussion of journalism ethics requires consideration of the context in which journalists now work. Chapters throughout this book both predict and prescribe how the bases of journalism ethics will and should evolve in today's global, digital age.

- International perspectives are crucial. Until recently, much scholarship on journalism ethics has come out of the United States and United Kingdom. The topic, however, is a global one that should be examined through multiple cultural lenses. Contributors to this volume come from nine countries in Europe and North America. Although a number of shared foundational values emerge in their work, authors offer a range of perspectives on the practice of journalism and journalism ethics.

- Newsrooms are important sites for investigation. A good deal of scholarly work has been done on the sociology of the newsroom, and it demonstrates the importance of the newsroom to journalists' work. Most of this scholarship, however, has not focused on ethical implications. Several chapters in this book both illuminate the strong influences of the newsroom on journalism ethics and make suggestions for how newsrooms of the future (either real or virtual) can become ethically healthier workplaces.

- Journalism ethics is individually, institutionally, and culturally based. The chapters in this volume demonstrate that an exploration of journalism ethics does not lead to a single influence but rather to multiple influences that work together in complex ways. David Pritchard's first essay, which presents the concept of normative ecologies, makes this argument explicitly, but it is implicit throughout the book. As all of the chapters demonstrate, journalism ethics is the result of multiple competing and complementary forces.

\section{A book in four parts}

If the book's themes serve to connect the chapters, the structure divides them. The book is organised into four parts, although the division is admittedly somewhat arbitrary; several of the chapters could easily fit into more than one part. As noted, David Pritchard's short first essay sets the stage for the four parts and 14 chapters that follow. In his essay, Pritchard discusses the domains that determine journalistic behaviour and the complex journalism ecologies that result from the interplay of those 
domains. Keep his ideas in mind as you move through the rest of the book.

\section{Part I. Spheres of influence: Fostering (or not) ethical journalism}

Part I focuses squarely on the topic of the Reuters conference and the title of the book: individual, institutional, and cultural influences - or domains - and the effects those can have on journalism ethics. The first two chapters, by Tony Harcup and Lee Wilkins, aim inward, exploring ethics in the newsroom and the forces that both contribute to and detract from ethical behaviour. Both authors use the News Corp phone hacking scandal as an example of the strong socialisation effects of the newsroom. In work that sparked passionate discussion at the Reuters conference, Tony Harcup uses testimony from the Leveson Inquiry to explore the tensions between individual and collective approaches to journalism ethics, and he argues that the two can coexist within an institutional setting. Drawing on feminist theory, Harcup contends that, if a culture of dialogue, openness and mutual respect can be fostered in newsrooms, both individual and collective responsibility can be called upon to create a framework for more ethical journalism. Lee Wilkins usefully takes ethicists outside of their normal comfort zone, examining the literature on business ethics and organisational change for insights into how organisational culture affects individual ethical choice. She finds that, although organisational culture does not replace individual thinking, it can either enhance or degrade individual ethical choice. Wilkins closes her chapter with a set of questions that can help scholars understand the influence that a newsroom's organisational climate can have on ethical decision-making.

Next, Part I turns to three short chapters by Mireya Márquez Ramírez, Bastiaan Vanacker, and Dejan Jontes that demonstrate the multiple influences journalists experience in their daily work. Each one features a case study that brings the cultural domain into the spotlight, while also recognising the role of individual and institutional forces. Mireya Márquez Ramírez gives us an intriguing glimpse into the changing nature of journalism in Mexico, particularly as it relates to attitudes about journalists accepting cash, gifts, and perks in exchange for news. Although the new generation of journalists working in post-authoritarian Mexico sees itself as a group of professionals committed to principles of autonomy and independence, Márquez Ramírez illustrates how these journalists 
work within nuanced and constantly changing standards. Her chapter reminds us that values, principles, and behaviours do not change overnight; history can be a powerful legacy. Bastiaan Vanacker reports on interviews he conducted with journalists in the United Kingdom, the Netherlands, and the Flanders region of Belgium that illuminate both shared and separate perspectives on journalism ethics, particularly as it relates to privacy issues. Vanacker's thought-provoking conclusion is that institutional factors contribute to a shared conception among journalists of their professional role and the principles that guide it. However, cultural differences lead to divergent ways of putting these shared principles into practice. Journalists in each country disagree about the limits of telling a particular story. Wrapping up Part I, Dejan Jontes engages in an insightful unpacking of journalism values in post-socialist Slovenia using two unusual but important sources: texts of award presentations and journalism textbooks. Through these two kinds of texts, Jontes finds an embrace of democratic journalistic values such as objectivity that have been imported from elsewhere and also, importantly, an understanding of non-partisanship that means resisting socialism and any remnants of it; this resistance, in fact, is represented as Slovene journalism's most important ethical value.

\section{Part II. Accountability mechanisms}

Part II includes three chapters that explore mechanisms of media accountability. Susanne Fengler, Tobias Eberwein, Julia Lönnendonker, and Laura Schneider-Mombaur begin with a broad look at journalists' perceptions of both traditional and emerging media accountability instruments. The results of their study, which impressively includes journalists from 14 countries, are somewhat discouraging. As they report, the impact of media accountability instruments is moderate at best. However, the authors offer some interesting ideas for approaches that could lead to more effective media accountability, including partnerships with the state - what they call government regulation of self-regulatory efforts. In his chapter, Carlos Maciá-Barber examines the role of a particular accountability instrument - the news ombudsman - and argues that this role can help reinforce the professional ethics of journalists while simultaneously promoting audience participation, media literacy, and the public's right to information. Maciá-Barber, who has studied the ombudsman function in news organisations around the world, outlines 
the most important conditions for effective ombudsmen and ends with a plea that, even in the face of ongoing challenges, ombudsmen should make all efforts to persevere. To finish Part II, Robert Drechsel, an accomplished media law scholar, looks at accountability from a legal perspective and poses an important question: has the professionalisation of journalism in America, which is centred on the idea of serving the public interest and is accompanied by ethical codes and standards, led journalism to a legally dangerous - and less free - place? In a systematic examination, Drechsel investigates two specific legal contexts - negligence and confidentiality and the ways in which these ethical standards may be transforming into legal standards. He ends with an exploration of the American context vis-à-vis Canada and the United Kingdom.

\section{Part III. Intersections: Theory and practice}

Part III includes three chapters that focus directly on the intersections between theory and practice. In their two chapters, Karen Slattery and Thomas Bivins apply the moral philosophies of deontology and virtue ethics - two philosophies firmly grounded in the autonomy of the individual as a moral agent - to journalism. David Allen and Elizabeth Blanks Hindman examine democratic theories and the different kinds of journalism each requires.

Karen Slattery's chapter focuses on the codes of ethics from three American journalism associations and the relationship between the principles expressed in those codes and the moral principles identified by deontologists such as Immanuel Kant and W. D. Ross. Slattery makes a persuasive and logical argument that, when journalism codes fail to offer clear resolutions to ethical dilemmas, deontological theory and the prima facie duties it presents can help clarify the most ethically justifiable choice. Thomas Bivins also examines American codes of ethics, but he chooses to look at the language of the earliest codes from the first part of the twentieth century. Language, Bivins argues, is central, and he takes the claim to heart in his compellingly written chapter. In the early codes, Bivins sees an appeal to virtue and good character that is missing from many of today's codes, which tend to be rules-based. This virtue-based approach, which is experiencing a resurgence thanks to the work of neoAristotelians such as Alasdair MacIntyre, may serve journalists and the public better. Bivins, therefore, recommends a return to a philosophical framework based on virtue that would allow individual journalists the 
leeway to make their own decisions based on overarching human virtues such as sincerity, competency, thoroughness, mercy, and moderation. Rounding out Part III is David Allen and Elizabeth Blanks Hindman's chapter on the centrality of democratic theory to journalism ethics. Their chapter succinctly and clearly describes three broad perspectives on democratic theory - elitist, discursive, and communitarian - and applies them to questions of journalism ethics. The authors then take a normative turn by suggesting that there is room for multiple conceptions of democracy along with multiple roles and responsibilities for journalism. The chapter ends with a nice pay-off: specific ideas about what roles different types of media may play based on the normative assumptions of the three different perspectives on democratic theory.

\section{Part IV. Emerging issues in a global, digital age}

The book's final chapters take a glimpse into journalism's future by investigating emerging issues in the global, digital age. Yael de Haan, Annemarie Landman, and Jan Lauren Boyles study real journalists' experiences in a rapidly changing work environment. Two other chapters - the first by Ejvind Hansen and the second by me and my co-author Tom Clasen - might be better categorised as thought experiments: Theoretically speaking, how can and should journalists adjust to this new landscape?

Yael de Haan, Annemarie Landman, and Jan Lauren Boyles focus on journalists in one Dutch newsroom, examining how the online era has introduced entirely new categories of news and information creators. From internet journalists who work in a traditional newsroom to citizen journalists who have no newsroom at all, the three authors demonstrate how these new creators of news are forcing legacy journalists to examine the standards upon which they have historically relied. The authors, who worked together after the Reuters conference to combine their two research projects, make a useful move from the descriptive - the focus of de Haan and Landman's work - to the normative - the focus of Boyle's work. To deal with the challenges arising from both within and outside the newsroom and to help ensure ethical journalistic practices, the authors propose a knowledge-centred newsroom model, which is focused on the ethics of collaboration. Ejvind Hansen's chapter also explores how journalism standards will be negotiated into the future. In one of the most philosophically sophisticated chapters of the book, Hansen asks whether the idea of journalism as the 'Fourth Estate', which is linked with clearly 
defined political nation states, can be transferred to an informational, economic, and political setting that has little affiliation with specific political units. In other words, if the Fourth Estate loses relevance in a transnational setting, what will ethical journalism mean, and who will and should - get to decide? Adopting a proceduralist approach, Hansen argues that journalists from across the world need to articulate a set of rules that don't prescribe specific standards but rather provide for the possibility of deliberating disagreements about those standards. The book closes with the chapter I co-wrote with Tom Clasen. Both of us have followed with interest and disappointment the steady reports of newsroom cutbacks. What, we wondered, would happen if the newsroom - the site that has been so central to journalists' identities - goes away? And what will it mean for journalism ethics if journalists find themselves working in more solitary settings? In the chapter, we investigate how the newsroom has affected journalism ethics in both beneficial and harmful ways. We end our chapter with a position we didn't expect going in: if journalism in the solitary age can hold onto the best parts of newsroom culture while leaving behind those that inhibit ethical practice, the solitary age could, in fact, enhance journalism ethics.

\section{Join the conversation}

During the Reuters conference, participants joined in a number of lively conversations through which we found much common ground. We certainly, however, didn't always agree. Questions about the strongest theoretical approaches, the most influential ethical forces, and the possibility of global standards took us in different directions. You'll find the same thing in this book: many points of agreement across the chapters but some disagreements as well. The point is not to solve all of the issues but rather to contribute to the conversation about journalism ethics - to get us a step closer to more fully understanding the multiple forces that influence journalists, news organisations, and media systems. Everyone in the room at Oxford and in this volume appreciates the essential role that journalism plays in people's lives. We are critics but also fans. It's my hope that others who care deeply about journalism will find our observations and ideas meaningful and that, together, we can offer ideas for making journalism better. 


\section{To purchase this book, or to see others in the}

Reuters Institute Challenges Series, please visit I.B.Tauris' website:

www.ibtauris.com/reuters 